\title{
УДК 621.565
}

\section{В.О. Когут, С.Д. Бутовський, М.Г. Хмельнюк}

Одеська національна академія харчових технологій, вул. Дворянська 1/3, м. Одеса, 65082

\section{ПРОМИСЛОВЕ ВИКОРИСТАННЯ СПОСОБУ КОНДЕНСАЦІЇ ВУГЛЕВОДНІВ В ЕЖЕКТОРІ ТЕПЛООБМІННИКУ}

У даній статті розглянута можливість застосування способу конденсації вуглеводнів в потоці в ежекторному теплообміннику на ділянках транспортування, зберігання, переливі з ємності в ємність і реалізачії в невеликих кількостях.

Ключові слова: ежектор теплообмінник - кавітаційний режим - конденсація вуглеводнів

\section{В.Е. Когут, Е.Д. Бутовский, М.Г. Хмельнюк}

Одесская н аичональная академия пищевых технологий, Дворянская 1/3, г. Одесса, 65082

\section{ПРОМЫШЛЕННОЕ ИСПОЛЬЗОВАНИЕ СПОСОБА КОНДЕНСАЦИИ УГЛЕВОДОРОДОВ В ЭЖЕКТОРЕ ТЕПЛООБМЕННИКЕ}

\begin{abstract}
В данной статье рассмотрена возможность применения способа конденсации углеводородов в потоке в эжекторном теплообменнике на участках транспортировки, хранении, переливе из емкости в емкость и реализации в небольших количествах.

Ключевые слова: эжектор теплообменник - кавитационный режим - конденсация углеводородов
\end{abstract}

\section{Kogut, I. Butovskyi, M. Khmelniuk}

Odessa national academy of food technologies, 1/3 Dvoryanskaya str., Odessa, 65082

\section{HYDROCARBON CONDENSATION METHOD IN THE EJECTOR EXCHANGER INDUSTRIAL UTILIZATION}

The possibility of applying of the hydrocarbons condensation method in the stream in the ejector heat exchanger in the areas of transportation, storage, or overflow from tank to tank and selling in small quantities is examined in the paper.

Keywords: ejector heat exchanger - cavitation mode - hydrocarbons condensation

\section{I. ВВЕДЕНИЕ}

Актуальной задачей топливно-энергетического комплекса Украины является сохранность углеводородов при их хранении и транспортировке. Задача сохранности на производстве решается практически полностью; а при вопросах транспортировки, переливе из емкости в емкость и хранении в газольдерах - практически не решается.
Все существующие потери углеводородов нефтепродуктов [1] можно разделить на несколько видов: количественные потери; качественноколичественные потери (потери от испарения), при которых происходит количественная потеря с одновременными ухудшениями качества продукта; качественные потери, когда ухудшается качество углеводородов при неизменном количестве.

\section{ПОТЕРИ УГЛЕВОДОРОДОВ НЕФТЕПРОДУКТОВ ОТ ИС-} ПАРЕНИЯ НА НЕФТЕБАЗАХ И АЗС

(на 1 куб. м. паровоздушной смеси до 1.2 кг топлива)

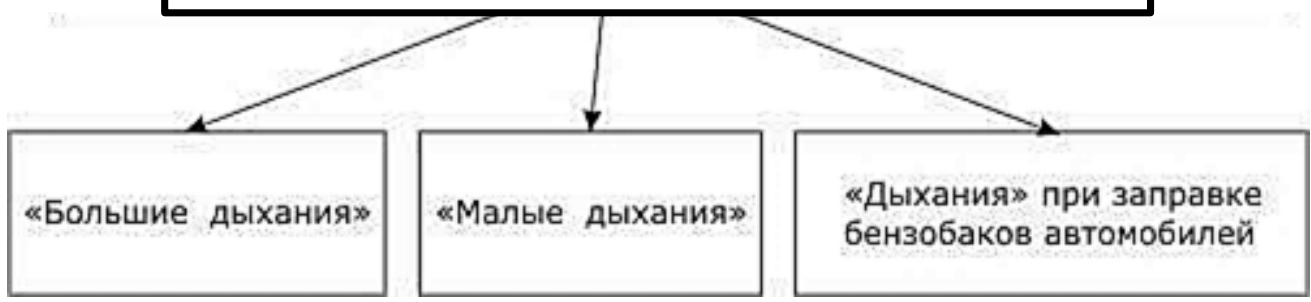

Рисунок 1 - Схема потерь углеводородов нефтепродуктов от испарения 
Tаблица 1 - Потери углеводородов нефтепродуктов в процентном соотношении

\begin{tabular}{|c|c|}
\hline Источники потерь & Потери, \% \\
\hline В резервуарах & 64,8 \\
\hline \multicolumn{2}{|c|}{ в том числе: } \\
\hline от «больших дыханий» & 54,0 \\
\hline от выдуваний & 0,6 \\
\hline от газового сифона & 0,9 \\
\hline при зачистке & 5,3 \\
\hline в насосных станциях & 2,3 \\
\hline с канализационными стоками & 7,5 \\
\hline В линейной части & 23,5 \\
\hline в том числе: & 22,3 \\
\hline от утечек & 1,2 \\
\hline от аварий & 1,84 \\
\hline
\end{tabular}

Одной из актуальных извечных проблем области транспортировки и хранения углеводородов является сокращение нормативных и сверхнормативных потерь углеводородов нефтепродуктов. Специалисты топливно-энергетического комплекса страны за последние годы достигли весомых результатов по снижению потерь, но величина этих потерь всё еще велика. Они заявляют, что потери углеводородов при разных дыханиях могут составлять 1-1.5\% от общего количества нефтепродуктов. При современном уровне развития технологий в транспортной, нефтегазовой сфере данная величина потерь не выглядит ужасающе, но в тоже время она всё еще остается достаточно высокой.

Нефтепродукты проходят сложный путь от месторождения до потребителя через этапы транспортировки, перевалки, хранения и распределения. Основываясь на различных источниках можно считать, что нефтепродукты на всём пути до потребителя проходят более чем 20 перевалок, на которых потери от испарения составляют 7,07,5\%, а от аварий и других утечек до 3,0\%.

\section{ІІ. АНАЛИЗ СИСТЕМ ТРАНСПОРТИРОВКИ}

Самым дешевым и экологически безопасным способом транспортировки нефтепродуктов являются магистральные трубопроводы для перекачивания углеводородов нефтепродуктов. Углеводороды нефтепродуктов в них движутся со скоростью до 3 м/сек под воздействием разницы в давлении, создаваемой насосными станциями. Их устанавливают с интервалом в 70-150 километров в зависимости от рельефа трассы. На расстоянии в 10-30 километров в трубопроводах размещают задвижки, позволяющие перекрыть отдельные участки при аварии. Внутренний диаметр труб, как правило, составляет от 100 до 1400 миллиметров. Их делают из высоко пластичных сталей, способных выдержать температурные, механические и химические воздействия. Постепенно все большую популярность обретают трубопроводы из армированного пластика. Они не подвержены коррозии и обладают практически неограниченным сроком эксплуатации. Поскольку применение трубопроводов экономически выгодно, а работают они в любую погоду и в любое время года, это средство транспортировки нефти действительно незаменимо.

Тем не менее, основной объем международных перевозок углеводородов нефтепродуктов и нефти осуществляют танкеры. Современные танкеры - это большие суда. Впечатляющие размеры объясняются экономическим «эффектом масштаба». Стоимость перевозки одного барреля нефтепродуктов на морских судах обратно пропорциональна их размерам. Поэтому большие корабли значительно сокращают расходы компаний на транспортировку.

Однако не все морские порты в состоянии принять у себя супер-танкер. Для таких гигантов нужны глубоководные порты. Нефть и углеводороды нефтепродуктов загружают в танкеры с берега, а разгрузку ведут при помощи корабельных насосов и трубопроводов, проложенных в танках и вдоль палубы. Однако супертанкеры дедвейтом более 250 тысяч тонн, как правило, просто не могут зайти в порт, будучи полностью загруженными. Их заполняют с морских платформ и разгружают, перекачивая жидкие углеводороды нефтепродуктов на танкеры меньшего размера. Еще один вид транспортировки углеводородов нефтепродуктов - по железной дороге. Однако для доставки «черного золота» по железной дороге требуется в 10 раз больше трудозатрат, чем для ее транспортировки по магистральным трубопроводам для перекачивания углеводородов нефтепродуктов. Поэтому даже в странах с разветвленной железнодорожной сетью этот способ перевозки нефти является второстепенным.

Транспортировка углеводородов нефтепродуктов на нефтеперерабатывающие заводы, и впоследствии, потребителю напрямую связана со значительными потерями, которые наносят ощутимый вред экономической составляющей топливноэнергетического комплекса Украины, а так же снижению эффективности производства углеводо- 
родов. При транспортировке и хранении испаряется большое количество углеводородов, особенно легких фракций с $\mathrm{C}_{1}$ до $\mathrm{C}_{6}$, что является основной причиной технологических потерь ценного сырья и вредных выбросов в окружающую атмосферу.

Согласно мировой статистике потери углеводородов нефтепродуктов при транспортировке значительно превышают потери при их хранении. Распределение потерь зависит от конкретного вида углеводородов типа объекта, в котором продукт находится (нефтебаза, резервуар, магистральный трубопровод и др.). Магистральные трубопроводы применяются для транспортировки нефтепродуктов от нефтебаз до конечного потребителя. Благодаря низкой стоимости транспортировки, магистральные трубопроводы для перекачивания углеводородов нефтепродуктов являются одним из важнейших способов транспортировки нефтепродуктов в топливно-энергетическом комплексе страны.

Сырую нефть транспортируют по маги- стральным трубопроводам от месторождений к нефтебазам, а также к магистральным терминалам. К терминалам танкеров или к нефтеперерабатывающим заводам нефть перекачивают по магистральным трубопроводам. Это бывает нужно, когда нефть перерабатывают не в районах ее добычи, а на значительном расстоянии от них, в непосредственной близости от рынков сбыта и главных потребителей.

Магистральные трубопроводы для перекачивания углеводородов нефтепродуктов обычно строят с диаметром от 5 до 20 см, длинные магистральные нефтепроводы могут быть диаметром до 120 см [7]. Самый протяженный трубопровод такого типа имеет диаметр 110 см и длину 4650 км. Он проложен в США от Хьюстона, что в штате Техас, до Нью-Йорка.

Обводные и параллельные трубопроводы помогают увеличить пропускную способность трубопроводов, имеющих меньший диаметр и построенных ранее [2].

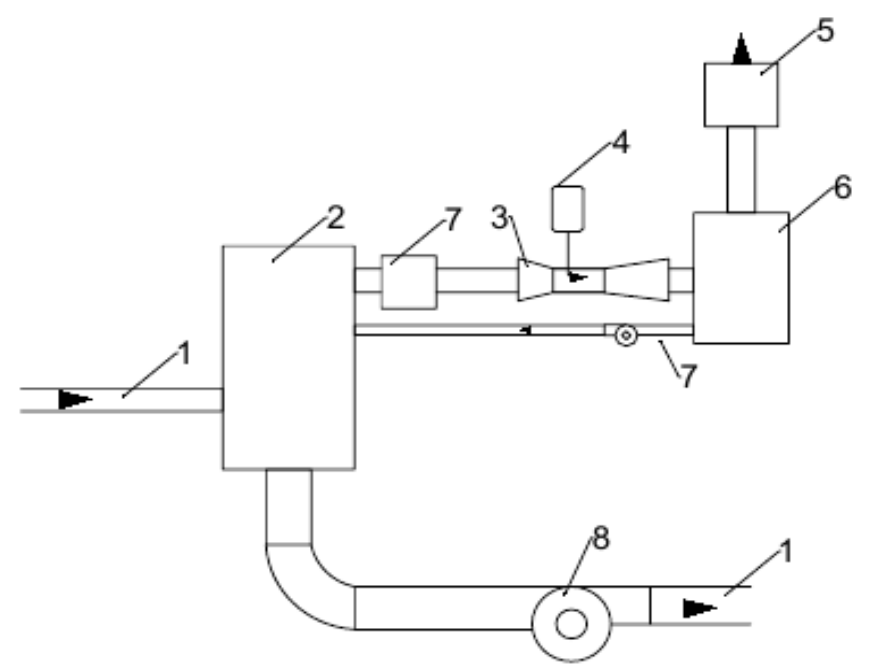

1 - основной магистральный трубопровод

2 - ресивер

3 - эжектор теплообменник

4 - устройство впрыскивающее инертный газ

5 - предохранительное устройство

6 - приёмная ёмкость

7 - нагнетатель

8 - насос

Рисунок 2 - Принциипильная схема подключения эжектора теплообменника в системе магистральных трубопроводов

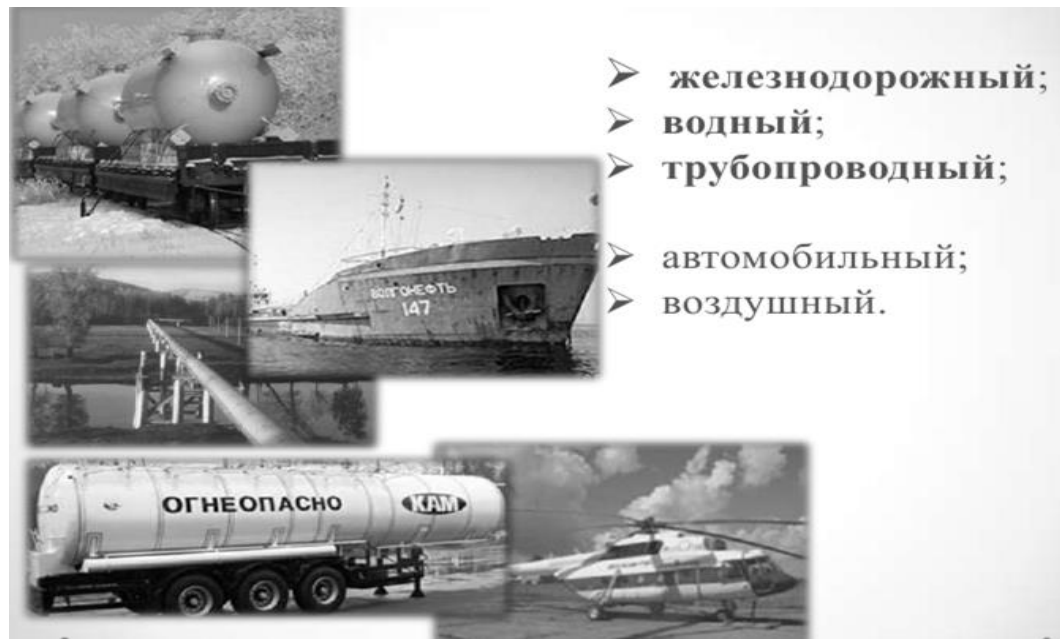

Рисунок 3 - Виды транспортировки жидких углеводородов 
Также для слива и налива углеводородов нефтепродуктов можно использовать эжектор теплообменник [3]. Использование данного устройства позволяет улучшить систему слива и налива и повысить энергетическую эффективность, которая играет важную роль в сохранности углеводородов.

При наличии паров углеводородов в жидкостном потоке на насосе может образоваться режим кавитации, который, в свою очередь, может привести к поломке рабочих элементов насоса. Для избегания этой причины необходимо сконденсировать пары углеводородов перед насосами. Данную задачу можно осуществить в предлагаемом схемном решении.

Основной магистральный трубопровод, перед насосом, подключается к ресиверу, которая служит отделителем жидкости. Из верхней части ресивера нагнетателем отбирается и ускоряется поток паров углеводородов до $20 \div 30$ м/с, и поступает на эжектор теплообменник, в который, через форсунку, впрыскивается жидкий инертный газ. На выходе из эжектора теплообменника жидкие охлажденные углеводороды поступают в приемную емкость. Из неё при помощи насоса возвращаются в ресивер. Ресивер с функцией отделителя жидкости обеспечивает парциальную работу основного перекачивающего насоса.

\section{III. СЛИВ УГЛЕВОДОРОДОВ С БОЛЬШИХ ЕМКОСТЕЙ}

Рост производства и потребления сжиженных углеводородных газов в современном мире вызывает большой интерес к вопросам их транспорта от кустовых баз сжиженных газов, газонаполнительных станций и газонаполнительных пунктов.

Процессы слива и налива различных нефтепродуктов достаточно сложны. Поэтому для их выполнения используются специальные установки и насосы. Слив и налив нефтепродуктов, по необходимости, может производиться из разнообразных резервуаров, цистерн, емкостей или танкеров при перевозке с помощью железнодорожного, водного или автомобильного транспорта. Оборудование для слива и налива нефтепродуктов служит непосредственно для соединения внутреннего объема резервуара с подводящими магистралями. Кроме того данный вид оборудования выполняет и предохранительные функции в случае возникновения аварийной ситуации в процессе заполнения или опорожнения того или иного резервуара. Профессиональная организация сливных и наливных операций обеспечивает экономичный перелив продукта, а также не допускает вытекание нефтепродуктов из ёмкостей во время хранения.
Следовательно, особенно важны задачи технического совершенствования процессов слива и налива на объектах и применение более эффективных технологических схем перекачки сжиженных газов.

Самый актуальный вопрос слива заключается в сливе углеводородов нефтепродуктов, обладающих повышенной вязкостью. Из-за повышения вязкости нефтепродуктов, становиться невозможным произвести слив обычным способом. Этот способ имеет опасные моменты: чрезмерное содержание воды нефтепродуктов, и опасность воспламенения. Повышенное содержание воды происходит из-за того, что пар конденсируется и смешивается с углеводородами нефтепродуктов, образуя всевозможные водные эмульсии. Для большинства углеводородов этот «побочный эффект» абсолютно недопустим, и в таком случае возникает актуальный вопрос о дополнительной очистке углеводородов от воды.

Одним из современных методов перекачивания сжиженных углеводородных газов является использование давления сжатого метана.

Метод перекачивания сжиженных углеводородных газов на кустовых базах сжиженных газов, газонаполнительных станциях и газонаполнительных пунктах с использованием давления сжатого метана позволяет работать по простой технологической схеме, в которой не используется дорогостоящее и сложное в эксплуатации компрессорное оборудование.

Операции слива и налива сжиженных углеводородных газов при этом осуществляются за счет избыточного давления сжатого метана, подаваемого в поровое пространство опорожняемого резервуара. При исследовании процесса слива и налива сжиженного пропана-бутана с помощью метана, необходимо найти время начала закачки метана в резервуар, потому что использование гидростатического напора в процессе слива и налива позволяет экономить метан, необходимый для слива.

На существующих кустовых базах, газонаполнительных станциях и газонаполнительных пунктах, использующих энергию сжатого метана для перемещения сжиженных углеводородных газов, узел регулирования вручную настраивается на постоянное давление метана 1,2-1,6 МПа не зависимо от температуры, давления, состава сжиженного газа, температуры наружного воздуха.

Также для слива и налива углеводородов нефтепродуктов из ёмкости в ёмкость при перекачивании насосами и обычном переливе можно использовать эжектор теплообменник [4].

Данную задачу можно осуществить в предлагаемом схемном решении. 


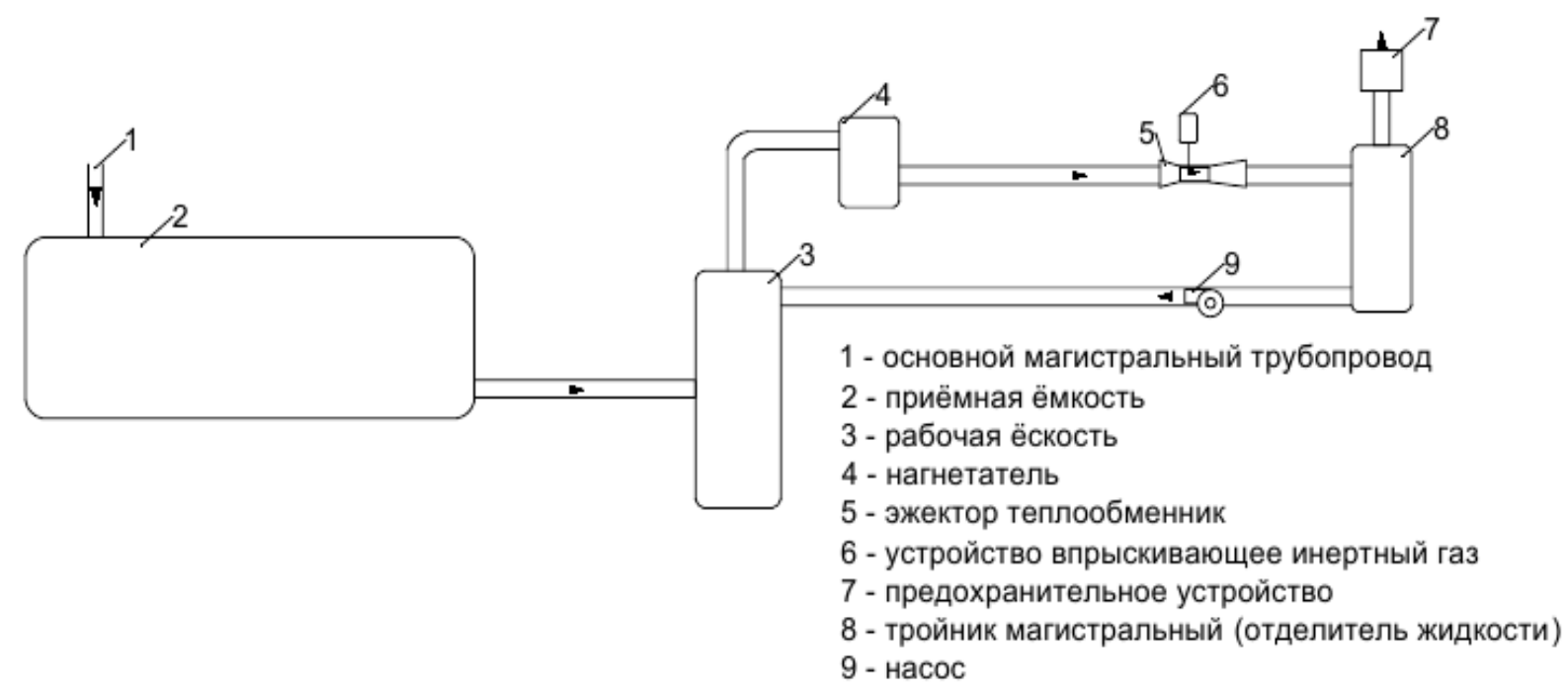

Рисунок 4 - Принциипильная схема подключения эжектора теплообменника в системе слива из емкости

\section{IV. АВТОЗАПРАВОЧНЫЕ СТАНЦИИ}

Использование эжектора теплообменника необходимо при заправке автомобильных баков топливом. Существующие заправочные станции в Европе оснащены линией забора паров углеводо- родов из баков и утилизации при помощи мембранных или абсорбционных устройств. Данная техническая возможность (линия забора паров) позволяет защитить окружающую среду, но не решает проблемы сохранения углеводородов. В Украине такие устройства не применяются.

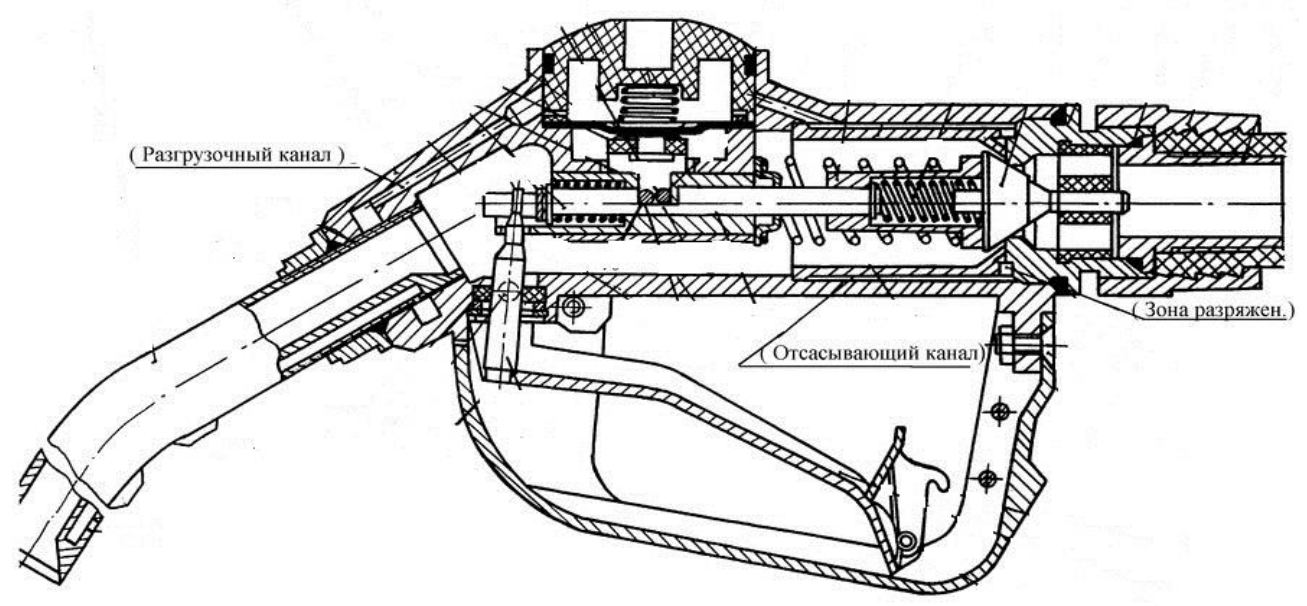

Рисунок 5 - Схема заправочного пистолета с отсосом паров

На рисунке 5 показана схема заправочного пистолета с отсосом паров на АЗС. Отсос паров происходит в накопительную ёмкость.

Предлагается устройство, позволяющее снизить потери углеводородов при переливе из емкости в емкость.

В рабочую схему АЗС, вместо устройства утилизации паров, подключается эжектор теплообменник, который подсоединен к разделителю, а тот в свою очередь подключен к ёмкости для хранения углеводородов, в которую происходит слив сконденсированных паров углеводородов.

На автомобильных заправочных станциях потери от испарения углеводородов при заправке автомобилей, на первый взгляд, незначительные. Но при дневной работе АЗС потери от испарения высокие, и зависят от температуры окружающей среды. 


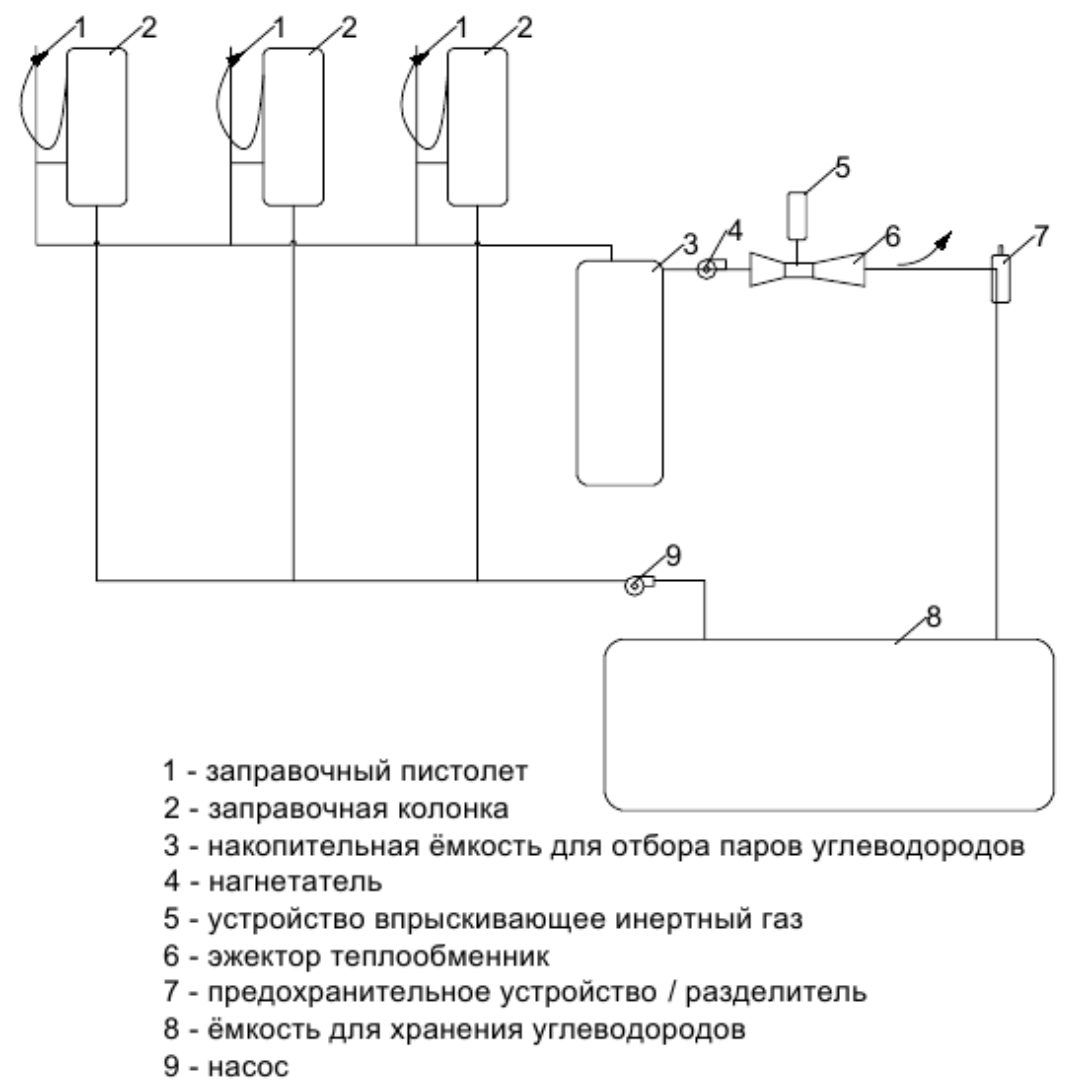

Рисунок 6 - Схема установки эжектора теплообменника на автомобильной заправочной станции

Таблица 2 - Содержание углеводородов в воздушной смеси в зависимости от температуры окружающей среды при переливе из емкости в емкость

\begin{tabular}{|l|c|c|c|}
\hline \multirow{2}{*}{ Вид топлива } & \multicolumn{2}{|c|}{ Температура окружающей среды, ${ }^{\circ} \mathrm{C}$} \\
\cline { 2 - 4 } & $0 \ldots 20$ & $20 \ldots 30$ & $30 \ldots 45$ \\
\hline Бензины обычных марок, $\%$ & $5 \ldots 7$ & $7 \ldots 12$ & $15 \ldots 20$ \\
\hline Дизельное топливо (летнее), $\%$ & $3 \ldots 4$ & $5 \ldots 6$ & $8 \ldots 10$ \\
\hline Биоэтанольное топливо, \% & $4 \ldots 5$ & $6 \ldots 10$ & $12 \ldots 22$ \\
\hline
\end{tabular}

\section{ВЫВОДЫ}

Одной из актуальных извечных проблем области транспортировки и хранения углеводородов является сокращение нормативных и сверхнормативных потерь углеводородов нефтепродуктов. Потери углеводородов при разных дыханиях могут составлять $1-1.5 \%$ от общего количества нефтепродуктов.

Нефтепродукты проходят сложный путь от месторождения до потребителя через этапы транспортировки, перевалки, хранения и распределения. Основываясь на различных источниках можно считать, что нефтепродукты на всём пути до потребителя проходят более чем 20 перевалок, на которых потери от испарения составляют 7.0$7.5 \%$, а от аварий и других утечек до $3.0 \%$.

При транспортировке и хранении испаряется большое количество углеводородов, особенно легких фракций с $\mathrm{C}_{1}$ до $\mathrm{C}_{6}$, что является основной причиной технологических потерь ценного сырья и вредных выбросов в окружающую атмосферу.

Распределение потерь зависит от характеристики продукта, вида объекта (нефтебаза, магистральный трубопровод) и характера перевалки нефтепродуктов. Поэтому одной из основных является проблема разработки и внедрения средств, сокращающих потери нефтепродуктов при их транспортировке и хранении.

Использование эжектора теплообменника способно решить задачу промышленности по сохранности углеводородов при хранении, и особенно при транспортировке нефтепродуктов, а так же при переливе из ёмкости в ёмкость.

В Украине подобных линий забора паров углеводородов не применяется.

Разработано устройство, позволяющее практически полностью снизить потери углеводородов при переливе из емкости в емкость, транспортировке. 


\section{ЛИТЕРАТУРА}

1. Потери нефти и нефтепродуктов при эксплуатации резервуарных парков. http:/gazovikneft.ru/ articles/poteri/, 2013.

2. Нефте- и газопроводы. Транспортировка газа. http://city-connect.ru/nefte-i-gazoprovody-transportirovka/, 2013.

3. В.Е. Когут, М.Г. Хмельнюк, Е.Д. Бутовский Охлаждающая система для конденсации углеводородов в потоке. - Холодильная техника и технология, №5 (145), 2013. - С. 23-27.

4. В.Е. Когут, Е.Д. Бутовский, Н.Г. Носенко Проектирование термоконденсатора эжектора. Холодильная техника и технология, №6 (146), 2013. - C. 45-48.

5. М.В. Лисанов, А.И. Гражданкин, А.В. Пчельников, А.В. Савин. Анализ риска аварий на нефтепроводных системах // Безопасность труда в промышленности. - 2006. - № 1 .

6. Промежуточный охладитель на основе термопрессора для агрегата АД-260 // Холодильная техника, №6, Москва, 1985, с. 21.

7. The American Society of Mechanical Engineers Pipelines Transportation Systems for Liquid Hydrocarbons and Other Liquids, ASME B31.4 - October, 2006.

\section{REFERENCES}

1. Loss of oil and petroleum tank farms in operation // http://gazovikneft.ru/articles/poteri/, 2013.

2. Oil and gas pipelines. Transportation of natural gas //http://city-connect.ru/nefte-i gazoprovody-transportirovka/, 2013

3. V.E. Kogut, M.G. Khmelniuk, I.D. Butovskyi Cooling system for condensing hydrocarbons in the flow // Refrigeration engineering and technology, №5 (145), 2013. - p. 23-27.

4. V.E. Kogut, M.G. Khmelniuk, I.D. Butovskyi. Designing thermo ejector condenser // Journal "Refrigeration engineering and technology”, №6 (146), 2013. - p. 45-48.

5. M.V. Lisanov, A.I. Grazhdankin, A.V. Pchelnikov, A.V. Savin. Accident risk analysis for oil pipeline systems // Journal «Safety in Industry» - 2006, № 1 .

6. Intercooler based termopressora unit for BP-260 // Journal «Refrigeration engineering», №6, Moskow, 1985, p. 21.

7. The American Society of Mechanical Engineers Pipelines Transportation Systems for Liquid Hydrocarbons and Other Liquids, ASME B31.4 - October, 2006.

\section{HYDROCARBON CONDENSATION METHOD IN THE EJECTOR EXCHANGER INDUSTRIAL UTILIZATION}

One of the actual problems of the transporting and storage of hydrocarbons is to reduce the regulatory and excessive losses of petroleum hydrocarbons. According to world statistics, losses during transportation of petroleum hydrocarbons significantly exceed the losses during storage. The losses caused damage to the economic factor of the fuel and energy complex of country, and reduce production efficiency. The distribution of losses depends on the characteristics of the product, the type of facility (tank farm, the main pipeline) and the nature of transshipment of oil products. Therefore, one of the main problems is the development and implementation of tools that reduce the loss of oil during transport and storage.

Keywords: ejector heat exchanger - cavitation mode-hydrocarbons condensation

Отримана в редакції 05.02.2014, прийнята до друку 04.03.2014 